\title{
Live capture and ownership of lemurs in Madagascar: extent and conservation implications
}

\author{
Kim E. Reuter, Haley Gilles, Abigail R. Wills and Brent J. Senall
}

\begin{abstract}
Overexploitation is a significant threat to biodiversity, with live capture of millions of animals annually. An improved understanding of live capture of primates is needed, especially for Madagascar's threatened lemurs. Our objectives were to provide the first quantitative estimates of the prevalence, spatial extent, correlates and timing of lemur ownership, procurement methods, within-country movements, and numbers and duration of ownership. Using semi-structured interviews of 1,093 households and 61 transporters, across 17 study sites, we found that lemur ownership was widespread and affected a variety of taxa. We estimate that 28,253 lemurs have been affected since 2010. Most lemurs were caught by owners and kept for either short ( $\leq_{1}$ week) or long ( $\geq_{3}$ years) periods. The live capture of lemurs in Madagascar is not highly organized but may threaten several Endangered and Critically Endangered species.
\end{abstract}

Keywords Africa, conservation, live capture, pet, primate, wildlife trade

\section{Introduction}

$\mathrm{O}$ verexploitation is a significant threat to biodiversity (Baillie et al., 2004), with hunting and live capture recorded throughout the tropics (e.g. Fa et al., 1995; Corlett, 2007). In tropical forests hunting is conducted on a small scale for subsistence, and as part of organized trade for domestic and international markets (Corlett, 2007). The bushmeat trade may be increasing with the human population (Corlett, 2007) and as rural communities gain access to urban markets (Fa et al., 1995; Duarte-Quiroga \& Estrada, 2003; Corlett, 2007). However, despite advances in understanding hunting, live capture of animals through informal and formal routes remains poorly understood (DuarteQuiroga \& Estrada, 2003; Nekaris et al., 2010).

Live capture may affect up to 4 million birds, 640,000 reptiles and 40,000 primates annually and the animals are traded globally (Karesh et al., 2005), usually to more affluent

Kim E. Reuter (Corresponding author), Haley Gilles and Brent J. Sewall Temple University, Department of Biology, 1900 N. 12th St, Philadelphia, PA 19122, USA. E-mail kim.reuter@temple.edu

Abigail R. Wills Mpingo Conservation \& Development Initiative, Kilwa Masoko, Tanzania

Received 24 March 2014. Revision requested 4 June 2014.

Accepted 29 August 2014. First published online 5 January 2015 or urban customers (Duarte-Quiroga \& Estrada, 2003; Corlett, 2007). In many cases, living animals are caught as part of trade networks for bushmeat and body parts, sometimes involving professional hunters, transporters and markets (Fa et al., 1995; Duarte-Quiroga \& Estrada, 2003; Corlett, 2007; Nekaris et al., 2010). This suggests that live capture, like the bushmeat trade, may be widespread and increasing.

Live capture is causing increasing concern in Madagascar (Schwitzer et al., 2013), where amphibians and reptiles are captured, sometimes to the point of near-extinction (e.g. Grenoble, 2013), and transported internationally via organized trade networks (Andreone et al., 2005) for pet or medical trades. In contrast, little is known about the live capture of the country's 197 native mammal species, $92 \%$ of which are endemic (IUCN, 2013). Most documented captures of mammals in Madagascar are related to the bushmeat trade (Golden, 2009; Razafimanahaka et al., 2012), although the trade appears to be less organized than in other countries (Golden, 2009). However, recent political instability may have resulted in increased trading of bushmeat (Schwitzer et al., 2014) and facilitated an increase in live captures. Effective conservation of Madagascar's mammals therefore requires a better understanding of the prevalence and breadth of the live capture of animals, including frequency, temporal trends, associated factors, and the extent to which movement of animals from the point of capture is facilitated by an established trade network.

In particular, this information is needed for Madagascar's endemic primates, the lemurs, which are one of the most threatened groups of large vertebrates (Schwitzer et al., 2014). Similar to other mammals, studies on lemur capture have focused on the bushmeat trade (e.g. Golden, 2009), which may be increasing following a coup d'état in 2009 (Schwitzer et al., 2014). However, lemurs are easy to habituate (Eppley et al., 2011) and thus may be attractive as pets. Furthermore, records of holding facilities for captive lemurs indicate that ownership of lemurs has been ongoing and may be common (Welch, 1996; Schwitzer et al., 2013). Although a small-scale study from the Union of the Comoros suggested that the pet trade is the primary anthropogenic threat to introduced mongoose lemurs Eulemur mongoz (Clark, 1997), the extent of live capture of lemurs has not been quantified.

The capture and sale of lemurs is illegal both domestically (Petter, 1969; Mittermeier et al., 2010) and internationally (UN, 1973), with punishments including confiscation (Welch, 1996). Despite formal restrictions on 
the capture and sale of lemurs, anecdotal reports of lemur ownership across north-west (Andrews et al., 1998), north-east (Goodman, 1993; Hekkala et al., 2007), east (Welch, 1996; Birkinshaw et al., 2007), south-east (Rajaonson et al., 2010), south (Jolly et al., 1982), south-west (Zinner et al., 2001; Sauther et al., 2013) and central (Nievergelt et al., 2002) Madagascar suggest that lemur ownership may be common and that regulations limiting lemur ownership are not enforced consistently.

Details about lemur ownership in Madagascar are scant. Anecdotal reports indicate that lemurs are kept in villages near forested areas (Zinner et al., 2001; Birkinshaw et al., 2007; Hekkala et al., 2007), potentially as a back-up source of meat for food security (Zinner et al., 2001). They are also kept by hotel owners (Goodman, 1993) to attract tourists (Schwitzer et al., 2013). The concept of lemurs as pets has been documented in Malagasy culture (Andrews et al., 1998; Sauther et al., 2013). In general, however, it is not clear how captive lemurs are obtained, to what extent they are moved in-country, or what happens to them postcapture. Given their threatened status (Schwitzer et al., 2014), such information is needed to inform conservation efforts (Mittermeier et al., 2010).

Our objectives were to (1) quantify the prevalence, spatial extent, correlates and timing of ownership, and (2) evaluate methods of procurement, movement around the country, the numbers kept and the duration of ownership. Based on the literature we hypothesized that (1a) many individuals would have owned a lemur or had knowledge of lemur ownership by others; (1b) lemur ownership would be widespread geographically and across taxa; (1c) the rate of lemur ownership would inversely correlate with human population density; and (1d) reports of lemur ownership would span the past few decades. The data collected were used to estimate the recent impact of lemur ownership in urban areas of Madagascar.

For the second objective we hypothesized that (2a) lemurs would be procured by owners through direct capture, and ( $2 \mathrm{~b})$ long-distance relocation of lemurs by means of public transport would be low, perhaps because of the illegal nature of lemur ownership; and if lemur ownership was more prevalent in (often) poorer rural areas the cost of keeping a lemur would result in (2c) most owners keeping only one or two individuals. Finally, because reports indicated lemurs were kept as a food resource or by hotel owners for display, we hypothesized that $(2 \mathrm{~d})$ durations of ownership would be relatively short ( $<1$ month) or relatively long ( $\geq_{1}$ year).

\section{Study area}

We collected data in cities and villages in central and northern Madagascar, between the capital city of Antananarivo and the northern regional capital of Antsiranana (Fig. 1).
The cities were located along a 1,092 $\mathrm{km}$ highway, and the villages were located around the perimeter of Ankarana National Park (18,22o ha), which supports a high density of primates (Hawkins et al., 1990) and may be a key source of pet lemurs.

\section{Methods}

International standards of research ethics were followed and research was approved by an ethics oversight committee (Temple University Institutional Review Board, Protocol Number: 21414, May 2013). All primary researchers completed ethics training through the Collaborative Institutional Training Initiative. Research was authorized by the Madagascar Ministry of Water and Forests, Madagascar National Parks, and locally elected officials.

\section{Data collection}

During June-August 2013 we visited households $(n=1,093)$ in 10 cities $(>5,000$ inhabitants) and seven villages $(\leq 5,000$ inhabitants $)$ in northern and central Madagascar (Fig. 1; Table 1). In villages we sampled every fifth household. In cities random sampling was stratified by administrative unit. To ensure independent sampling only one person was interviewed per household. Respondents were head-of-household (self-identified as having major buying power for household goods) adults ( $\geq 18$ years). If an eligible individual refused to participate or if nobody was present, sampling continued at the next household. Interviews were anonymous and no identifying information was collected. Interviewees were reminded that questions could remain unanswered, the interview could be terminated at any point, and participation was voluntary. Verbal informed consent was received and interviewees chose the place, time and language (French or local Malagasy dialect) of the interview. Interviews were conducted by a two-person team comprising an international project leader trained in ethical data collection and a trained Malagasy translator. Malagasy translators were always members of the predominant ethnic group of a study site, always fluent in the local Malagasy dialect, and never known to the interviewee.

To investigate the in-country movement of captive lemurs, interviews $(n=61$; Table 1$)$ were conducted in city bus stations and ports that specialized in intercity transport. Buses are the primary means of intercity transportation in Madagascar. Individuals identified as vehicle drivers were asked to participate, and anonymity and informed consent were ensured. Villages did not have permanent bus stations or ports, and therefore no transportation interviews were conducted at these sites.

During 20-minute semi-structured interviews (RietbergenMcCracken \& Narayan, 1998) we provided participants with 

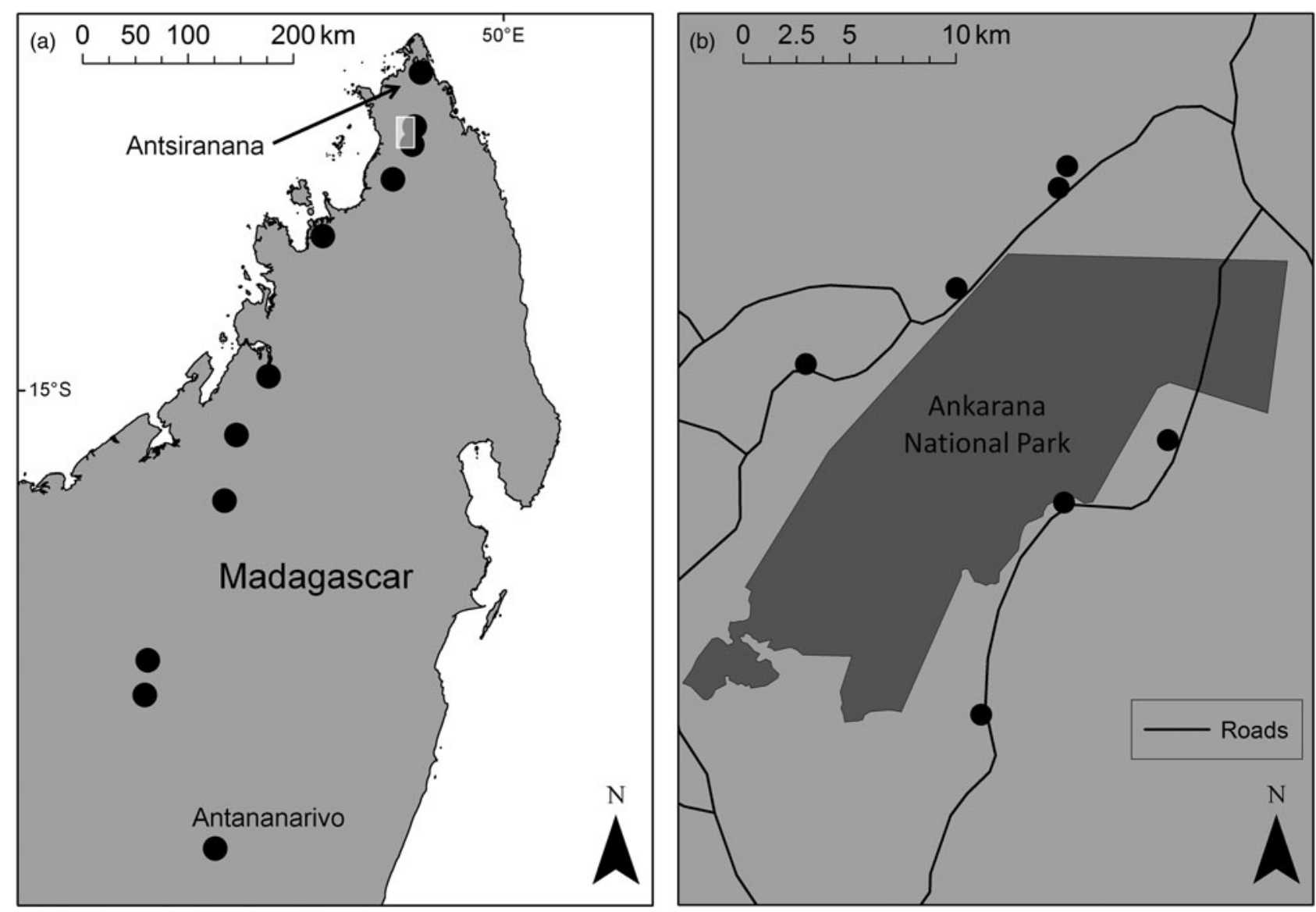

FIG. 1 (a) Cities in central and northern Madagascar, and (b) villages in the vicinity of the Ankarana National Park, where interviews were conducted. The shaded rectangle on (a) shows the location of (b) in northern Madagascar.

broad definitions of raising, purchasing and catching wild animals (raising was defined as keeping an animal alive for any period of time). Interviewees were asked whether they had ever seen a pet or raised lemur, using locally appropriate words for raise (miompy in Merina dialect, mitarimigna in Sakalava/Antakarana) and pet (animaux domestiques in French, biby fiompy in Merina, biby tarimiana in Antakarana). If the answer was yes, we asked: Where, when and how many did you see? We did not ask individuals whether they had owned a lemur, because of the illegal nature of the activity and the potential for increased interviewee discomfort. However, some interviewees indicated voluntarily that they were current or former owners. In such cases we asked the following questions: How did you procure the lemur? How long did you have your pet lemur? Why did you stop keeping a pet lemur? Drivers at transportation hubs were asked: Have you ever transported a lemur? If the answer was yes: Was the lemur alive? What distance did you transport it? How much did you charge to transport it?

When speaking with interviewees we defined a pet lemur as any lemur that was perceived as belonging to an individual or a business, regardless of the purpose of its captivity.
This included habituated, restrained and/or unrestrained lemurs that were cared for by an owner, but did not include fully wild lemurs living on privately owned land. The concept of owning a habituated pet (such as a domestic cat) is understood in Madagascar; respondents differentiated between free-roaming lemurs and habituated lemurs with an owner. We explicitly excluded captive lemurs in zoos. Interviewees could rarely identify the species of a captive lemur, and early interviews showed that providing images of lemurs did not result in consistent identification. Occasionally species identification was possible based on direct observation of the captive lemur or through the use of local or scientific names.

We conducted a literature search, in English, of firsthand reports of captive lemurs (excluding hunting, bushmeat and poaching) in Madagascar, comprising a search of ISI Web of Science, using the search terms 'pet* OR own ${ }^{*}$ OR captive* AND lemur* AND Madagascar'; a Google Scholar search, for its flexibility in surveying literature across a wide variety of disciplines (keywords 'pet lemur Madagascar'); and a search of Lemur News (keywords 'pet', 'pets', 'captive'), where researchers commonly share anecdotal reports. 
TABLE 1 The 10 cities and seven villages in Madagascar (Fig. 1) where interviews were conducted, with population, number of households interviewed, number of individuals who knew someone who owned or had previously owned a lemur, number of individuals who themselves owned or had previously owned a lemur, number of drivers interviewed, and number of drivers who had transported captive lemurs. Data from the villages are aggregated under Ankarana Park Perimeter Zone to protect respondents' identities. Population estimates for cities were obtained from the Ilo Project (2003) and for villages from local officials. Blank cells indicate no data or that no interviews were conducted.

\begin{tabular}{|c|c|c|c|c|c|c|}
\hline Study site & Population & $\begin{array}{l}\text { No. of households } \\
\text { interviewed }\end{array}$ & $\begin{array}{l}\text { No. that know someone } \\
\text { who owns/has owned a } \\
\text { lemur }(\%)\end{array}$ & $\begin{array}{l}\text { No. of current/for- } \\
\text { mer owners }(\%)\end{array}$ & $\begin{array}{l}\text { No. of drivers } \\
\text { interviewed }\end{array}$ & $\begin{array}{l}\text { No. of drivers who } \\
\text { had transported pet } \\
\text { lemurs (\%) }\end{array}$ \\
\hline \multicolumn{7}{|l|}{ Cities } \\
\hline Ambanja & 28,468 & 55 & $28(50.9)$ & $6(10.9)$ & 8 & $0(0)$ \\
\hline Ambilobe & 56,427 & 99 & $31(31.3)$ & $3(3.03)$ & 4 & $0(0)$ \\
\hline Andrevorevo & & 40 & $20(50.0)$ & $1(2.5)$ & & \\
\hline Andriba & 32,000 & 74 & $3(4.05)$ & $6(8.11)$ & & \\
\hline Aniverano Nord & 6,622 & 90 & $29(32.22)$ & $0(0)$ & & \\
\hline Antsohihy & 105,317 & 60 & $37(61.67)$ & $4(6.67)$ & 1 & $0(0)$ \\
\hline Antananarivo & $1,054,649$ & 199 & $71(35.68)$ & $2(1.01)$ & 18 & $0(0)$ \\
\hline Antsiafabositra & 8,328 & 69 & $2(2.89)$ & $9(13.04)$ & & \\
\hline Antsiranana (Diego Suarez) & 87,569 & 180 & $33(18.33)$ & $6(3.33)$ & 30 & $3(10)$ \\
\hline Tsararivotra & & 32 & $10(31.25)$ & $0(0)$ & & \\
\hline Total (cities) & & 898 & $\begin{array}{c}264(31.83 ; 95 \% \text { CI } \\
19.8-43.86)\end{array}$ & $\begin{array}{c}37(4.86 ; 95 \% \mathrm{CI} \\
2.01-7.71)\end{array}$ & 61 & $\begin{array}{l}3(2 ; 95 \% \text { CI }-1.92- \\
5.92)\end{array}$ \\
\hline \multicolumn{7}{|l|}{ Villages } \\
\hline Ankarana Park Perimeter Zone & & 192 & $\begin{array}{c}41 \text { (17.84; } 95 \% \text { CI } \\
0.76-34.92)\end{array}$ & $0(0)$ & $\begin{array}{l}\text { No bus stations or } \\
\text { ports }\end{array}$ & $\begin{array}{l}\text { No bus stations or } \\
\text { ports }\end{array}$ \\
\hline Ambondromifehy & 5,000 & & & & & \\
\hline Andranankoho & 2,000 & & & & & \\
\hline Ampasinbengy & 1,997 & & & & & \\
\hline Lambondry & 120 & & & & & \\
\hline Marotaolana & 175 & & & & & \\
\hline Matzaborimanga & 400 & & & & & \\
\hline Tsarakibany & 250 & & & & & \\
\hline Total (villages and cities) & & 1,093 & $\begin{array}{c}305(26.07,95 \% \mathrm{CI} \\
15.86-36.28)\end{array}$ & $\begin{array}{c}37(2.86,95 \% \mathrm{CI} \\
0.84-4.88)\end{array}$ & 61 & $\begin{array}{l}3(2,95 \% \text { CI }-1.92- \\
5.92)\end{array}$ \\
\hline
\end{tabular}




\section{Analysis}

As there may be greater variation between than within study sites, interviewees were used as subsamples within each study site for most analyses, except for subsets of the data with low sample size (owners of lemurs, $n=37$; bus drivers who had transported them, $\mathrm{n}=3$ ). Results are presented as mean values with $95 \%$ confidence intervals. For mixed effects logistic regressions $95 \%$ CI was set at twice the standard error.

We used a mixed effects logistic regression for hypothesis $1 \mathrm{c}$ and examined two alternate models. Each model had a random effect of study site (city or village) plus a single fixed effect: the continuous variable $\ln$ (population size) (i.e. natural logarithmically transformed population size) or the categorical variable type of study site (city or village). Population size was natural log transformed to increase model stability. The effect of $\ln$ (population size) on whether a respondent self-reported lemur ownership was also modelled. We did not examine the effect of type of study site on self-reported ownership because all self-reported owners were in cities. Analyses were completed using $R$ v. 3.o.2 (R Development Core Team, 2013) with the lme4 package (Bates et al., 2013).

We estimated the total number of captive lemurs held in urban households since 2010 by extrapolating the frequency of lemur ownership at our urban sites. We assumed conservatively that only one lemur was owned per individual, representing one household. Based on Madagascar's urban population (7.27 million people; UNDP, 2013) and mean urban household size (4.4 people per household; INSTAT \& ORC Macro, 2005), there are c. 1,652,272 urban households in the country.

Price-related data are presented in Malagasy ariary, with U.S. dollar equivalents in parentheses, based on the exchange rate of 1 June 2013 (MGA 2,197 to USD 1; United Nations Treasury, 2014). For comparison, $81.3 \%$ of the population lives on $<$ USD 1.25 per day (UNDP, 2013).

Village data are aggregated for anonymity. Interviewees did not always give mutually exclusive answers, or know or provide the information requested. Therefore, sample sizes vary but are clearly indicated.

\section{Results}

In accordance with hypothesis $1 \mathrm{a},>25 \%$ of interviewees (26.07\%, 95\% CI 15.86-36.28) had seen a captive lemur; in three locations most respondents had knowledge of lemur ownership (Table 1). However, the mean percentage of individuals at a study site who reported currently or formerly owning a lemur was low $(2.86 \%, 95 \%$ CI $0.91-4.81$; Table 1$)$.

In accordance with hypothesis $1 \mathrm{~b}$, reports of lemur ownership were geographically widespread (Fig. 2). Respondents had seen captive lemurs in many areas of Madagascar in

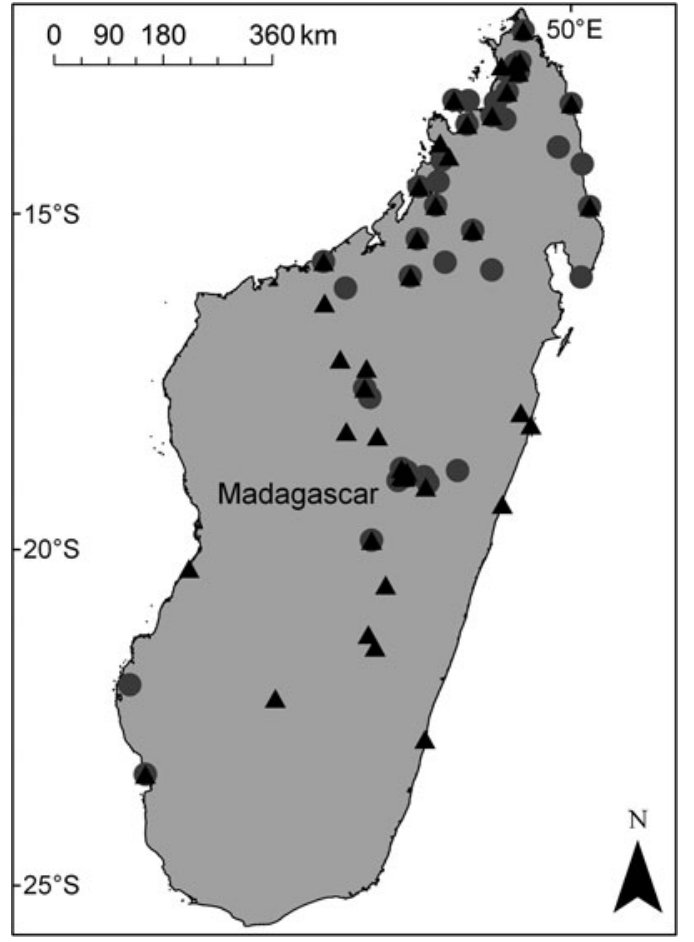

FIG. 2 Locations in Madagascar where respondents reported having seen pet lemurs during 2010-2013 (circles) and during 1960-2010 (triangles).

2009 and earlier (prior to the 2009 coup d'état) and in 2010 and later (following the 2009 coup d'état; Table 2; Fig. 2). We and other authors (Table 2) identified several taxa in four families that have been kept in captivity but, given the difficulties in accurate species identification, it was not possible to determine which taxa were most commonly and least commonly held captive.

In contrast to hypothesis $1 \mathrm{c}$, the human population size at a study site did not affect whether a respondent had ever seen a captive lemur (mixed effects logistic regression, $\ln$ (population size $)=0.25,95 \% \mathrm{CI}-0.5-0.55, \mathrm{P}=0.097$ ) or whether a respondent had owned a lemur (mixed effects logistic regression, $\ln ($ population size $)=0.40,95 \% \mathrm{CI}$ $-0.08-0.88, \mathrm{P}=0.098)$. However, our results supported hypothesis $1 \mathrm{c}$ when population size was examined as a categorical effect. Specifically, respondents in cities were more likely to have seen a captive lemur than respondents in villages (mixed effects logistic regression, type of study site(city) $=1.64,95 \% \mathrm{CI} 0.03-3.25, \mathrm{P}=0.041)$. All self-reported lemur owners were from cities.

Most people ( $92 \%$ of $n=305)$ and most owners $(84 \%$ of $\mathrm{n}=37$ ) could recall the date of seeing or owning a captive lemur, and many of these encounters had occurred since 2010 ( $63 \%, 95 \%$ CI 49-77; and 43\%, respectively). In accordance with hypothesis $1 \mathrm{~d}$, respondents noted having seen pet lemurs in every decade since 1960, whereas respondents reported personal ownership of lemurs in every decade since 1980. 
TABLE 2 Sightings of pet lemurs in Madagascar for which species or genus was identified, with location, year, and notes on taxon identification.

\begin{tabular}{|c|c|c|}
\hline Lemur* & Location (year) & Notes \\
\hline \multicolumn{3}{|l|}{ Cheirogaleidae } \\
\hline $\begin{array}{l}\text { Cheirogaleus sp. or Microcebus sp. } \\
\text { (tsitsihy) }\end{array}$ & Tsararivotra (2000) & $\begin{array}{l}\text { Respondent identified lemur by local name; } \\
\text { genus identified using Harcourt \& Thornback } \\
\text { (1990) }\end{array}$ \\
\hline \multicolumn{3}{|l|}{ Indriidae } \\
\hline Avahi laniger & Sahalanona (2009) & Rajaonson et al. (2010) \\
\hline $\begin{array}{l}\text { Propithecus sp. (tsibahaka, black } \\
\text { and white lemur) }\end{array}$ & Andriba $(2010,2011)$ & $\begin{array}{l}\text { Respondents identified lemur species in a } \\
\text { guidebook }\end{array}$ \\
\hline \multicolumn{3}{|l|}{ Lemuridae } \\
\hline Eulemur collaris & Berenty (1980) & Jolly et al. (1982) \\
\hline \multirow[t]{3}{*}{ Eulemur coronatus } & Antsiranana (2013) & Personally observed by authors \\
\hline & Ankarana Perimeter Zone (2013) & \\
\hline & Anivorano Nord (2013) & \\
\hline Eulemur fulvus & Morondava region (1999) & Zinner et al. (2001) \\
\hline \multirow[t]{3}{*}{ Eulemur sanfordi } & Antsiranana (2013) & Personally observed by authors \\
\hline & Anivorano Nord (2013) & \\
\hline & Ambilobe (2013) & \\
\hline \multirow[t]{2}{*}{ Eulemur macaco } & Antsiranana (2013) & Personally observed by authors \\
\hline & Ambilobe (2013) & \\
\hline Hapalemur alaotrensis & Lac Alaotra (year unknown) & Mittermeier et al. (2010) \\
\hline \multirow[t]{2}{*}{ Hapalemur griseus } & Lac Alaotra $(1997,1999)$ & Nievergelt et al. (2002); Mutschler et al. (2001) \\
\hline & Toamasina $(2005)$ & Birkinshaw et al. (2007) \\
\hline \multirow[t]{2}{*}{ Hapalemur occidentalis } & Ambanja (1983) & Respondents identified lemur species in \\
\hline & Antsiranana (Diego Suarez, 2011) & guidebook \\
\hline Hapalemur sp. (bamboo lemur) & Antsohihy (2013) & $\begin{array}{l}\text { Respondent identified bamboo lemur as the } \\
\text { type of lemur seen in captivity }\end{array}$ \\
\hline \multirow[t]{12}{*}{ Lemur catta (ring-tailed lemur) } & $\begin{array}{l}\text { Ambohitsoabe (Miadanandriana, } \\
\text { 1990) }\end{array}$ & $\begin{array}{l}\text { Respondents identified pets as ring-tailed } \\
\text { lemurs }\end{array}$ \\
\hline & Ambohimanarina (1980) & \\
\hline & Ambositra (2000) & \\
\hline & Ankazobe & \\
\hline & Befotaka (2010) & \\
\hline & Fianarantsoa (1985) & \\
\hline & Mahajanga (1995) & \\
\hline & Toamasina (year unknown) & \\
\hline & Tulear $(2013,2009)$ & \\
\hline & Votamandry (1980) & \\
\hline & Morondava region (1999) & Zinner et al. (2001) \\
\hline & Tulear (2012) & Sauther et al. (2013) \\
\hline \multirow[t]{3}{*}{ Varecia variegata } & Ile Sainte Marie (1991) & Goodman (1993), \\
\hline & Near Maroantsetra (1998) & Hekkala et al. (2007) \\
\hline & Masoala (year unknown) & Vasey \& Tattersall (2002) \\
\hline \multicolumn{3}{|l|}{ Lepilemuridae } \\
\hline Lepilemur sp. & Antsiranana (2013) & Personally observed by authors \\
\hline Lepilemur dorsalis & Nosy Be (1995) & Andrews et al. (1998) \\
\hline
\end{tabular}

*Includes lemur taxa that were named by respondents or described in sufficient detail to permit identification, personally observed and identified by our research team, or recorded as pets in scientific literature. The list is probably incomplete, given that most respondents did not know species names and were unable to describe qualitative features of the lemurs in sufficient detail to facilitate species identification.

In cities $1.71 \%$ (95\% CI $0.71-2.71)$ of interviewees had owned a lemur since 2010, although only o.6\% (95\% $\mathrm{CI}=0.3^{-0.9)}$ of individuals owned a lemur for $\geq 3$ years during this time. If our urban study sites are representative of cities throughout Madagascar we therefore estimate that
28,253 lemurs have been held in captivity since 2010, with 9,913 of these held for at least 3 years.

Thirteen of 37 owners reported the method of procurement of their lemur(s). In accordance with hypothesis $2 a$, the majority of owners procured their lemur(s) by direct 


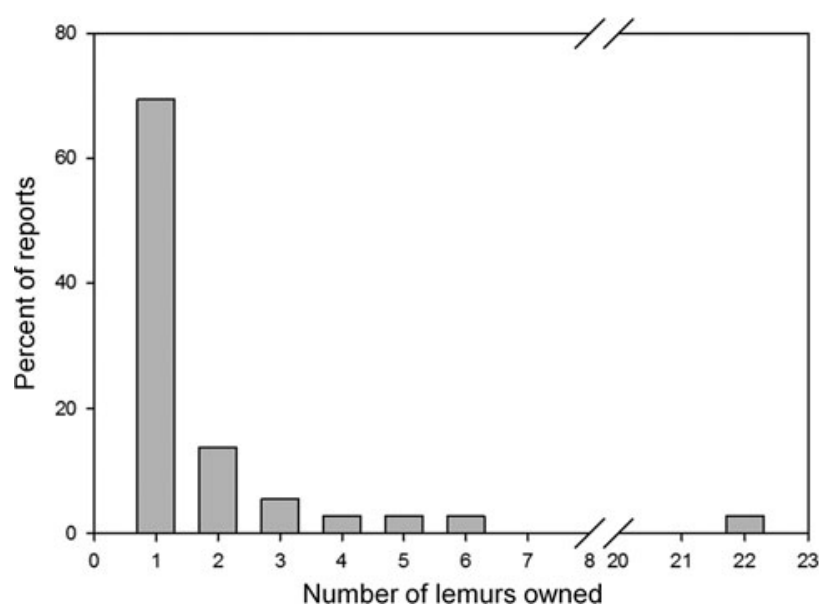

FIG. 3 Distribution of the number of lemurs owned by all self-reported lemur owners $(n=37)$.

capture (46\%), although some had bought lemurs (31\%) or received them as gifts (23\%). Owners who had captured their lemurs indicated that the lemurs came from forested areas $(n=4)$ or were captured using a rope trap $(n=1)$ or after being habituated by gold miners $(n=1)$. Of the owners who had purchased their lemurs, three reported prices: MGA 3,000 (USD 1.03) per lemur from the French Mountain Protected Area near Antsiranana; MGA 3,000 (USD 1.03) from a dalaly (travelling merchant) in Antsohihy; and MGA 30,000 (USD 13.65) from an individual in Antananarivo.

In accordance with hypothesis $2 \mathrm{~b}$, few $(\mathrm{n}=3)$ intercity drivers had ever transported a live lemur (Table 1). All three were interviewed in Antsiranana and had transported live lemurs as recently as 2012 or 2013. The mean distance travelled was 41.8 $\mathrm{km}$ (95\% CI 14.3-69.3; range 15.0-62.4 km). Two of the three drivers had only ever transported one lemur and did not charge for the service. In contrast, the third driver estimated transporting one lemur every 3 months. It was not clear whether this was the same lemur being moved repeatedly or different individuals. The driver charged MGA 2,000 (USD o.91) to transport one lemur $63 \mathrm{~km}$. Overall, drivers did not charge an extra fee for personal baggage, including animals and meat transported for personal use.

Most lemur owners (97\%) told us how many lemurs they had owned. In accordance with hypothesis $2 c$, most of these households (68\%) had owned only one lemur and the mean number of lemurs owned was 2.14 per household (95\% CI 0.96-3.32; range 1-22; Fig. 3).

Ten owners reported the duration of ownership as 1.17 years $\left(95 \% \mathrm{CI}=0.05^{-2.29}\right)$. However, as predicted by hypothesis $2 \mathrm{~d}$, most owners reported having their lemurs for $\leq 1$ week $(50 \%)$ or $\geq 3$ years $(30 \%)$. Some $(20 \%)$ had owned their lemur for 2-6 months.

Eleven owners provided twelve explanations why they stopped keeping lemurs (one individual had owned more than one lemur and gave two different answers). Some (45\%) said that their lemurs escaped; two sold the lemurs for MGA 10,000 (USD 4.55) each. In other cases the lemurs died $(n=2)$, were given away $(n=1)$, were killed for misbehaving $(n=1)$, or were returned to the forest $(n=1)$.

\section{Discussion}

\section{Extent of ownership}

It is difficult to acquire data on the in-country acquisition, trade and ownership of live primates (Nijman et al., 2011). To our knowledge no previous study has quantified the prevalence and distribution of in-country ownership of endemic primates, although studies have estimated the number of primates sold in local markets (Ceballos-Mago et al., 2010; Shepherd, 2010), quantified the number of captive primates in religious settings (Eudey, 1994), examined characteristics of primate owners (Jones-Engel et al., 2005), and quantified densities of urban, free-living primate populations (Kyes et al., 2011). Our data indicate that knowledge of captive lemurs is common in Madagascar and a small but not insubstantial percentage of respondents have owned a lemur. Furthermore, lemur ownership is ongoing and is geographically widespread in the country.

\section{Patterns of ownership}

The rates at which respondents reported having seen or owned captive lemurs were higher in cities than in villages, although increasingly larger cities did not have correspondingly higher rates. Our city-village comparisons should be interpreted with caution because some respondents referred to seeing and/or owning lemurs in a different location to where they were interviewed. Nonetheless, our results indicate lemur ownership is common in urban areas.

Given the (presumably) greater access to lemurs' natural habitat from villages, the reasons for lower rates of ownership in villages are unclear. It is possible that lemurs are captured in remnant habitats and transported to cities, where owners may have more resources to keep them. Alternatively, our results may have been influenced by local factors at our study sites, including environmental education efforts that may have convinced residents not to capture lemurs (Madagascar National Parks, pers. comm.) or caused them to conceal their participation in such activities. Local cultural beliefs, including an aversion to hunting lemurs (Cardiff \& Befourouack, 2003), may also have influenced behaviour.

The reported durations of lemur ownership suggest a dichotomy in motivation, although we did not examine this explicitly. Short ownership may be attributable to lemurs being held temporarily in rural areas prior to consumption 
(a)

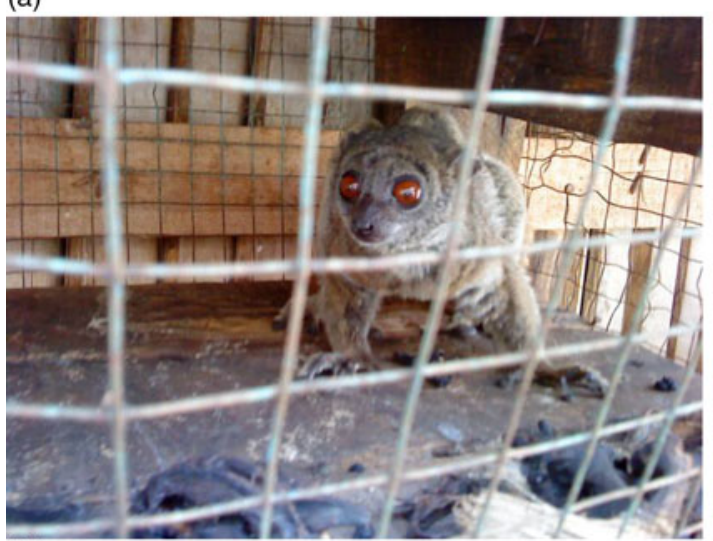

(b)

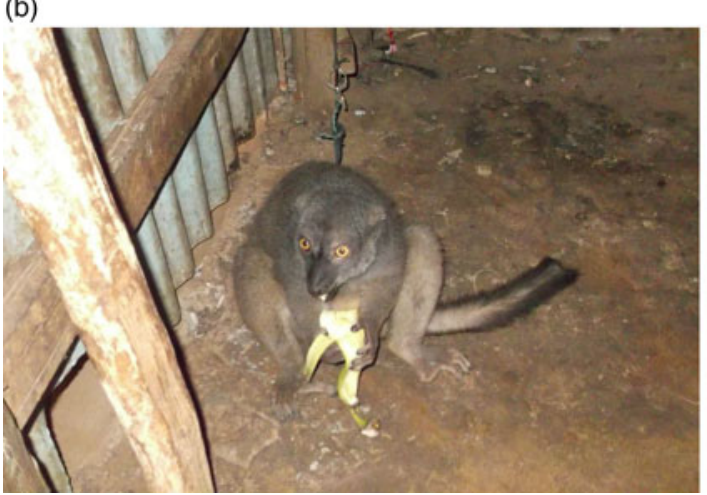

(c)

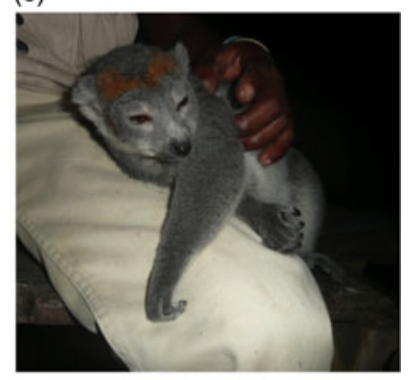

(d)

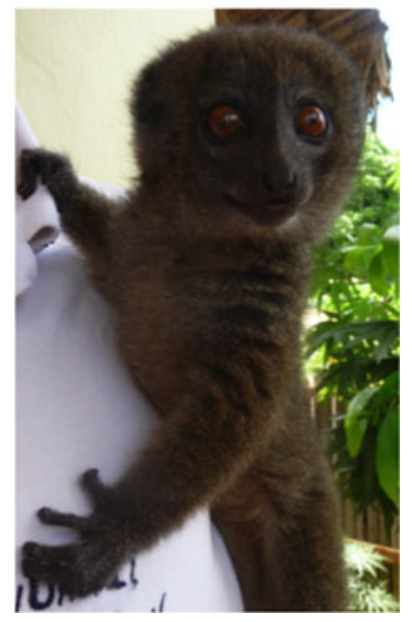

Plate 1 Photographs of pet lemurs, taken with interviewee consent. (a) Lepilemur sp., held in a cage at a private residence. (b) Eulemur sp., restrained with a rope at a restaurant. (c) Eulemur coronatus male with its owner in a city. This lemur was not restrained but was highly habituated (image courtesy of Elodie Camprasse). (d) Habituated lemur being held by a tourist at a higher-end hotel (image courtesy of Olivier Raynaud).
(Zinner et al., 2001) or sale, or the difficulties in keeping some species (such as folivores) alive for long periods of time (Junge et al., 2009; Mittermeier et al., 2010). In Indonesia the motivations for keeping primates as pets may relate to professional status or religion (Jones-Engel et al., 2005), and in Mexico City empathy and a desire to possess a primate, as well as social status, were important motivating factors (Duarte-Quiroga \& Estrada, 2003).

Well-established, high-volume markets are often highly organized (Andreone et al., 2005; Shepherd, 2010). In Madagascar the movement of domestic meat from rural areas to urban markets occurs through middlemen and can involve coordinated transfers of cash and meat across hundreds of kilometres (KER, unpubl. data). In contrast, and aligned with Golden's (2009) statements about the informal nature of bushmeat trade in Madagascar, we found no evidence that live capture of lemurs involved the use of dedicated transport mechanisms or middlemen in a consistent manner. Although information may have been concealed, respondents never mentioned sellers capturing and selling lemurs as a regular business; lemurs were sometimes transported using regular passenger buses and typically were owned by the same person who captured them. This contrasts with the trade of live-captured amphibians in Madagascar (Andreone et al., 2005) and the black-market trade of primates in other regions (Duarte-Quiroga \& Estrada, 2003; Shepherd, 2010).
Similar to the primate trade in Mexico City (DuarteQuiroga \& Estrada, 2003) and Venezuela (Ceballos-Mago et al., 2010), lemur ownership in Madagascar was not limited to foreigners living in Madagascar; in contrast, foreigners living in the Union of the Comoros have been hypothesized to be the primary owners of pet lemurs there (Tattersall, 1998). People keep lemurs despite being aware that this is illegal, which may suggest that enforcement is limited. Captive lemurs may be prevalent because of the low cost of obtaining native species from local habitats (Duarte-Quiroga \& Estrada, 2003); our price data, similar to those of Sauther et al. (2013), indicate that the cost of purchasing a lemur and transporting it to a city is less than a typical day's income in Madagascar.

\section{Animal welfare}

Captive lemurs were kept in a variety of settings (Plate 1) and were sometimes exploited as for-profit attractions (Schwitzer et al., 2013). Lemurs were often kept in cramped conditions and given food that was inconsistent with their natural diet, including rice and bananas. Respondents often described lemurs in positive terms, comparing their hands, eyes and size to those of children, and some owners expressed higher esteem for their pet lemurs than for other domestic animals (e.g. dogs). These responses may be 
associated with cultural beliefs that lemurs are closely related to, or represent, humans (KER, pers. obs.; Jones et al., 2008). The positive attitudes towards lemurs are similar to those expressed in a study of primates in Mexico (Duarte-Quiroga \& Estrada, 2003).

\section{Conservation implications}

Our estimate that 28,253 lemurs may have been held in captivity in Madagascar since 2010 is significant given the threatened status of many species of lemurs as a result of habitat destruction and hunting (Mittermeier et al., 2010). At least four species have been reduced to $<500$ individuals, and a further nine species to $<10$, 000 individuals in total (IUCN, 2013). The true number of captive lemurs may be higher than our estimate but further study is needed to confirm this, as we extrapolated our estimates to regions outside the study area. Lemur ownership continues at these levels despite increases in conservation awareness, area of protected habitat, and spending on lemur-related outreach (Schwitzer et al., 2014).

Although lemur capture is generally detrimental to wild populations, it could potentially play a role in conservation efforts (Schwitzer et al., 2013) through programmes aimed at the reintroduction of threatened species, maintaining genetic diversity in species whose wild populations are disappearing, and serving as a focus of environmental education. For such outcomes to occur some form of legalization of lemur ownership may be required; there are indications that the government of Madagascar may regulate some captive facilities in the future (Schwitzer et al., 2013). In this scenario for-profit businesses could enter a permitting process that would require inspections, minimum standards for captivity facilities to ensure animal health, and limiting ownership to species known to fare well in captivity (Schwitzer et al., 2013). The legalization and regulation of private ownership would be more difficult but could include more consistent enforcement, using fines and a citizens' reporting process, and a strict registration and permitting process combined with regular monitoring. The potential of such efforts, however, is unlikely to be realized unless legal frameworks, enforcement mechanisms, and monitoring efforts are reinforced and implemented on a much broader scale, and substantially more funding and personnel are made available. Any legalization initiative should proceed with caution to avoid complicating enforcement efforts and weakening existing protection of lemurs.

Lemur species are not all equally represented in captive ownership. For instance, there were no reports of ownership of the widely distributed aye-aye Daubentonia madagascariensis, perhaps because it is associated with negative taboos throughout much of its range (Mittermeier et al., 2010), including our rural study sites (Cardiff \& Befourouack, 2003). However, even low rates of live capture may be a threat for species with few individuals or subpopulations remaining (e.g. Eulemur sanfordi and Eulemur coronatus). Likewise, wild populations of large-bodied species (e.g. Varecia variegata), which tend to have low reproductive rates (Harvey \& Clutton-Brock, 1985), may have low capacity to respond to removal of individuals. Comparative studies are needed to ascertain how the impacts of live capture vary between lemur species, and to understand how such impacts compare to those of habitat change, hunting and other threats.

Our work is a first step towards quantifying the live capture of lemurs, informing efforts to conserve lemur populations, and clarifying means to regulate lemur ownership effectively. Our findings indicate that lemur ownership is common and widespread, and that a large number of threatened or otherwise susceptible taxa may be affected. They also highlight the importance of quantifying ownership of endemic primates in other tropical countries, especially where they are facing additional anthropogenic threats such as hunting and habitat change.

\section{Acknowledgements}

We thank T.E. Janvier, S. Hanitriniaina, J. Randrianarivelo, T.R. Belalahy and C. Barat for their translation services, host communities for their hospitality, two anonymous reviewers for assistance with this article, and the Madagascar Institute for the Conservation of Tropical Environments for assistance with permits. All opinions, findings, conclusions and recommendations expressed are those of the authors and do not necessarily reflect the views of the National Science Foundation (NSF). This material is based upon work supported by the NSF Graduate Research Fellowship under Grant DGE-1144462 to KER, NSF grant DEB-1257916 to BJS, an Explorers Club Grant to KER, and a Temple University Faculty Senate grant to BJS.

\section{References}

Andreone, F., Cadle, J.E., Cox, N., Glaw, F., Nussbaum, R.A., Raxworthy, C.J. et al. (2005) Species review of amphibian extinction risks in Madagascar: conclusions from the Global Amphibian Assessment. Conservation Biology, 19, 1790-1802.

Andrews, J., Antilahimena, P. \& Birkinshaw, C.R. (1998) Use of a day testing box by a wild sportive lemur, Lepilemur dorsalis, on Nosy Be, north-western Madagascar. Folia Primatologica, 69(suppl. 1), $18-21$.

Baillie, J.E.M., Hilton-Taylor, C. \& Stuart, S.N. (eds) (2004) 2004 IUCN Red List of Threatened Species. A Global Species Assessment. IUCN, Gland, Switzerland, and Cambridge, UK.

Bates, D., Maechler, M., Bolker, B. \& Walker, S. (2013) lme4: Linear mixed-effects models using Eigen and $S_{4}$. R package version 1.o-5. Http://cran.r-project.org/web/packages/lme4/index.html [accessed 6 March 2014].

Birkinshaw, C., Ravoahangy, A. \& Andriamaharoa, H.E. (2007) Lemur records at priority sites for plant conservation. Lemur News, $12,35-36$. 
Cardiff, S. \& Befourouack, J. (2003) The Reserve Speciale d'Ankarana. In The Natural History of Madagascar (eds S. Goodman \& J.P. Benstead), pp. 1501-1507. University of Chicago Press, Chicago, USA.

Ceballos-Mago, N., González, C.E. \& Chivers, D.J. (2010) Impact of the pet trade on the Margarita capuchin monkey Cebus apella margaritae. Endangered Species Research, 12, 57-68.

Clark, M. (1997) The mongoose lemur Eulemur mongoz on Anjouan, Comores. Dodo, Journal of The Wildlife Preservation Trusts, 33, $36-44$.

Corlett, R.T. (2007) The impact of hunting on the mammalian fauna of tropical Asian forests. Biotropica, 39, 292-303.

Duarte-Quiroga, A. \& Estrada, A. (2003) Primates as pets in Mexico City: an assessment of the species involved, source of origin, and general aspects of treatment. American Journal of Primatology, 61, 53-60.

Eppley, T.M., Verjans, E. \& Donati, G. (2011) Coping with low-quality diets: a first account of the feeding ecology of the southern gentle lemur, Hapalemur meridionalis, in the Mandena littoral forest, southeast Madagascar. Primates, 52, 7-13.

Eudey, A.A. (1994) Temple and pet primates in Thailand. La Terre et la Vie-Revue d'Écologie, 49, 273-280.

Fa, J.E., Juste, J., Perez del Val, J. \& Castroviejo, J. (1995) Impact of market hunting on mammal species in Equatorial Guinea. Conservation Biology, 9, 1107-1115.

Golden, C.D. (2009) Bushmeat hunting and use in the Makira Forest, north-eastern Madagascar: a conservation and livelihoods issue. Oryx, 43, 386-392.

Goodman, S.M. (1993) A reconnaissance of Ile Sainte Marie, Madagascar: the status of the forest, avifauna, lemurs and fruit bats. Biological Conservation, 65, 205-212.

Grenoble, R. (2013) Ploughshare tortoise smugglers caught with 10 percent of entire species at Thailand airport. Http://www. huffingtonpost.com/2013/03/28/ploughshare-tortoise-smugglethailand_n_2972673.html [accessed 6 March 2014].

Harcourt, C. \& Thornback, J. (eds) (1990) Lemurs of Madagascar and the Comoros. The IUCN Red Data Book. IUCN, Cambridge, UK.

Harvey, P.H. \& Clutton-Brock, T.H. (1985) Life history variation in primates. Evolution, 39, 559-581.

Hawkins, A.F.A., Chapman, P., Ganzhorn, J.U., Bloxam, Q.M.C., BARLOW, S.C. \& TONGE, S.J. (1990) Vertebrate conservation in Ankarana Special Reserve, northern Madagascar. Biological Conservation, 54, 83-110.

Hekkala, E.R., Rakotondratsima, M. \& Vasey, N. (2007) Habitat and distribution of the ruffed lemur, Varecia, north of the Bay of Antongil in northeastern Madagascar. Primate Conservation, 22, 89-95.

Ilo Project (2003) The Commune Census, 2001. Http://www.ilo. cornell.edu/ilo/data.html [accessed 6 March 2014].

instat (Institut National de la Statistique) [MAdagascar] \& ORC Macro (2005) Enquête Démographique et de Santé, Madagascar 2003-2004: Rapport de synthèse. INSTAT and ORC Macro, Calverton, USA.

IUCN (2013) IUCN Red List of Threatened Species v. 2013.2. Http:// www.iucnredlist.org [accessed 6 March 2014].

Jolly, A., Oliver, W.L.R. \& O'Connor, S.M. (1982) Population and troop ranges of Lemur catta and Lemur fulvus at Berenty, Madagascar: 1980 census. Folia Primatologica, 39, 115-123.

Jones, J.P.G., Andriamarovololona, M.M. \& Hockley, N. (2008) The importance of taboos and social norms to conservation in Madagascar. Conservation Biology, 22, 976-986.

Jones-Engel, L., Schillaci, M.A., Engel, G., Paputungan, U. \& Froehlich, J.W. (2005) Characterizing primate pet ownership in Sulawesi: implications for disease transmission. In Special
Topics in Primatology Volume 4. Commensalism and Conflict: The Human-Primate Interface (eds J.D. Patterson \&

J. Williams), pp. 113-137. The American Society of Primatologists, Seattle, USA.

Junge, R.E., Williams, C.V. \& Campbell, J. (2009) Nutrition and behavior of lemurs. Veterinary Clinics of North America: Exotic Animal Practice, 12, 339-348.

Karesh, W.B., Cook, R.A., Bennett, E.L. \& Newcomb, J. (2005) Wildlife trade and global disease emergence. Emerging Infectious Diseases, 11, 1000-1002.

Kyes, R.C., Feeroz, M.M., Aziz, M.A., Alam, S.M.R., Aкhtar, F., Ahmed, S. et al. (2011) Preliminary population survey of the rhesus macaques in Barmi Bazaar, Bangladesh: survey approaches for studying urban primates. American Journal of Primatology, 73 (Suppl. 1), 88.

Mittermeier, R.A., Louis, JR, E.E., Richardson, M., Schwitzer, C., Langrand, O., Rylands, A.B. et al. (2010) Lemurs of Madagascar. 3 rd edition. Conservation International, Arlington, USA.

Mutschler, T., Randrianarisoa, A.J. \& Feistner, A.T.C. (2001) Population status of the Alaotran gentle lemur Hapalemur griseus alaotrensis. Oryx, 35, 152-157.

Nekaris, K.A.I., Shepherd, C.R., Starr, C.R. \& Nijman, V. (2010) Exploring cultural drivers for wildlife trade via an ethnoprimatological approach: a case study of slender and slow lorises (Loris and Nycticebus) in South and Southeast Asia. American Journal of Primatology, 72, 877-886.

Nievergelt, C.M., Pastorini, J. \& Woodruff, D.S. (2002) Genetic variability and phylogeography in the wild Alaotran gentle lemur population. Evolutionary Anthropology, 11, 175-179.

Nijman, V., Nekaris, K.A.I., Donati, G., Bruford, M. \& Fa, J. (2011) Primate conservation: measuring and mitigating trade in primates. Endangered Species Research, 13, 159-161.

Petter, J.J. (1969) Speciation in Madagascan lemurs. Biological Journal of the Linnean Society, 1, 77-84.

R Development Core Team (2013) R: A language and Environment for Statistical Computing. R Foundation for Statistical Computing, Vienna, Austria.

Rajaonson, A., Ratolojanahary, M., Ratsimbazafy, J., Feistner, A. \& King, T. (2010) Enquête préliminaire de la distribution des lémuriens de bambou dans et autour du Corridor forestier Fandriana-Vondrozo, Madagascar. Lemur News, 15, 34-39.

RaZafimanahaKa, J.H., Jenkins, R.K.B., Andriafidison, D., Randrianandrianina, F., Rakotomboavonjy, V., Keane, A. \& Jones, J.P.G. (2012) Novel approach for quantifying illegal bushmeat consumption reveals high consumption of protected species in Madagascar. Oryx, 46, 584-592.

Rietbergen-McCracken, J. \& Narayan, D. (1998) Participation and Social Assessment: Tools and Techniques. World Bank, Washington, DC, USA.

Sauther, M.L., Cuozzo, F.P., Youssouf Jacky, I.A., Fish, K.D., LaFleur, M., Ravelohasindrazana, L.A.L. \& Ravoavy, J.F. (2013) Limestone cliff-face and cave use by wild ring-tailed lemurs (Lemur catta) in southwestern Madagascar. Madagascar Conservation \& Development, 8, 73-80.

Schwitzer, C., King, T., Robsomanitrandrasana, E., Chamberlan, C. \& Rasolofoharivelo, T. (2013) Integrating ex situ and in situ conservation of lemurs. In Lemurs of Madagascar: A Strategy for their Conservation 2013-2016 (eds C. Schwitzer, R. A. Mittermeier, N. Davies, S. Johnson, J. Ratsimbazafy, J. Razafindramanana et al.), pp. 146-152. IUCN SSC Primate Specialist Group, Bristol Conservation and Science Foundation, and Conservation International, Bristol, UK. 
Schwitzer, C., Mittermeier, R.A., Johnson, S.E., Donati, G., Irwin, M., PeAcock, H. et al. (2014) Averting lemur extinctions amid Madagascar's political crisis. Science, 343, 842-843.

Shepherd, C.R. (2010) Illegal primate trade in Indonesia exemplified by surveys carried out over a decade in North Sumatra. Endangered Species Research, 11, 201-205.

Tattersall, I. (1998) Lemurs of the Comoro Archipelago: status of Eulemur mongoz on Moheli and Anjouan, and of Eulemur fulvus on Mayotte. Lemur News, 3, 15-17.

UN (1973) Convention on International Trade in Endangered Species of Wild Fauna and Flora. United Nations, Washington, DC, USA.

UNDP (2013) Human Development Report 2013: The Rise of the South: Human Progress in a Diverse World. United Nations Development Programme, New York, USA.

United Nations Treasury (2014) UN Operational Rates of Exchange. Http://treasury.un.org/operationalrates/ OperationalRates.aspx [accessed 4 June 2014].

Vasey, N. \& Tattersall, I. (2002) Do ruffed lemurs form a hybrid zone? Distribution and discovery of Varecia, with systematic and conservation implications. American Museum Novitates, 3376, 1-26.
Welch, C. (1996) Projects at Ivoloina and Betampona in eastern Madagascar. Lemur News, 2, 11

Zinner, D., Ostner, J., Dill, A., Razafimanantsoa, L. \& RASOLOARISON, R. (2001) Results of a reconnaissance expedition in the western dry forests between Morondava and Morombe. Lemur News, 6, 16-18.

\section{Biographical sketches}

Kim ReUteR's interests include the study of the trade in wildlife, natural resource use, and conservation in sub-Saharan Africa. HaLey GiLlEs has investigated fatal bird-surface collisions in urban areas and the absence of lemur populations outside protected areas in Madagascar. ABigail Wills has researched subsistence use of mangrove products in northern Madagascar and currently works on forest conservation and community development projects in Tanzania. BRENT SEWALL's research focuses on the ecology and conservation of threatened vertebrates and forest and cave communities in sub-Saharan Africa and North America. 